\title{
Oxidative stress and antioxidant activity of female rat liver tissue after sevoflurane anaesthesia: young versus old
}

\author{
Arslan $\mathrm{M}^{1}$, Isik $\mathrm{B}^{1}$, Kavutcu $\mathrm{M}^{2}$, Kurtipek $\mathrm{O}^{3}$ \\ Gazi University Faculty of Dentistry, Department of Oral and Maxillofacial Surgery Ankara, Turkey. \\ marslan36@hotmail.com
}

\begin{abstract}
Aim: The aim of our study was to assess the evidence of oxidative stress in the rat liver tissue by studying enzymes, such as nitric oxide synthase (NOS), superoxide dismutase (SOD), glutathione-S transferase (GST) activity, and thiobarbutiric acid-reactive substances (TBARS) levels in young versus old female rats after sevoflurane anaesthesia.

Material and method: The study involved 28 female Wistar Albino rats. The rats were divided into the two groups [(Group I, n=14): Young sevoflurane group (Group I-YS, n=7); Young control group (Group I-YC, n=7)], [(Group II, $n=14$ ): Old sevoflurane group (Group II-OS, $n=7$ ); Old control group (Group II-OC, n=7)]. Sevoflurane was administered at $2 \%$ volume inspiratory concentration, 6 L.min-1 in $100 \% \mathrm{O} 2$ for 2 hours. The control groups were not subjected to any procedures. Accordingly, GST, SOD, and NOS enzyme activity and TBARS level, were studied in the liver tissue samples of the rats to determine the presence of oxidative stress (OS) and antioxidant activity. Results: Following administration of sevoflurane anaesthesia; GST, SOD enzyme activity and TBARS level was significantly higher in the Group I-YS than in the Group I-YC and in the Group II-OS than in the Group II-OC. There was no difference between the groups when the mean NOS levels were compared. Conclusion: Although the results of our study are similar to the previous indicating that sevoflurane has the capacity to induce the oxidative stress; a new data has been recorded that sevoflurane has a similar effect on the OS level in aged and young female rat (Tab. 1, Fig. 4, Ref. 48). Full Text in PDF www.elis.sk. Key words: oxidative stress, liver tissue, rat, sevoflurane, GST, SOD, NOS, TBARS.
\end{abstract}

Postoperative hepatic injury has been reported after an exposure to volatile anaesthetics, especially halothane. The injury is usually seen few days after the exposure and is characterized by malaise, fever, jaundice, eosinophilia and marked elevation in serum transaminases, which occasionally ends with massive liver necrosis and death (1). Hepatic injury was seen more often in females, obese middle-aged women than in males (2-4).

Volatile agents are known to have an adverse effect on hepatic antioxidant defense mechanism as well as on accelerating peroxidation (5). As a result, volatile agents are assumed to cause some structural changes in hepatic tissues (6). Oxidative stress (OS) arises due to an imbalance between the production and elimination of free oxygen radicals that are generated during aerobic metabolism and consumed endogenously.

Sevoflurane is a comparatively recent addition to the range of inhalational anaesthetics. It has a low blood solubility, which results in a rapid induction and faster recovery (7). Although there are reports of sevoflurane-associated liver injury in the literature (8-13), sevoflurane is considered less hepatotoxic than the older inhalational agents (14).

${ }^{1}$ Gazi University Faculty of Dentistry, Department of Oral and Maxillofacial Surgery Ankara, Turkey, ${ }^{2}$ Gazi University Medical Faculty, Department of Medical Biochemistry, Ankara, Turkey, and ${ }^{3}$ Gazi University Medical Faculty, Department of Anesthesiology and Reanimation, Ankara, Turkey

Address for correspondence: M. Arslan, MD, Gazi University Faculty of Dentistry, Anesthesiology and Reanimation Specialist, Department of Oral and Maxillofacial Surgery, Emek 06510 Ankara, Turkey.
Several studies reported the effects of sevoflurane anaesthesia on postoperative liver functions in surgical patients $(15,16)$, however, there are no reports on the effects of sevoflurane on liver functions in old versus young female patients.

The aim of our study was to assess the evidence of OS in the rat liver tissue by studying enzymes, such as nitric oxide synthase (NOS), superoxide dismutase (SOD), glutathione-S transferase (GST) activity, and thiobarbutiric acid-reactive substances (TBARS) levels in young female rats versus old female rats after sevoflurane anaesthesia.

\section{Material and method}

The study was performed upon the approval of Erciyes University Medical School Ethics Committee in Erciyes University Experimental and Clinical Research Center (DEKAM).

The study involved 28 female Wistar Albino rats (14 young (5 months old) and 14 old (12 months old)) with a weight of 175$210 \mathrm{~g}$ raised under the same conditions. The rats had free access to food and water until 2 hours before anaesthesia procedure and were kept in a room temperature of $20-24{ }^{\circ} \mathrm{C}$ with a rhythm of 12-hour light and 12-hour darkness. Before the study was started, the anesthetic agent vaporizer was calibrated. Anaesthetic agent was set at a minimum alveolar concentration (MAC) of 1 and 2 $\%$ sevoflurane volume (17). The anaesthesia procedure was conducted in the groups of rats (per group) in a transparent plastic container of $40 \times 40 \times 70 \mathrm{~cm}$ in size. The container, which allowed 
for observation of the rats, was connected to a half open anaesthesia machine (AMS, Senior 425) with static hoses. The anaesthetic agent was released into the container in $100 \% \mathrm{O}_{2}$.

The rats were divided into the main two groups as young and old groups. These two groups were further divided into the two subgroups as sevoflurane and control groups. The control groups were not subjected to any procedures.

Group I (young), n=14

a) Young sevoflurane group (Group I-YS, n=7)

b) Young control group (Group I-YC, n=7)

Group II (old), n=14

a) Old sevoflurane group (Group II-OS, $n=7$ )

b) Old control group (Group II-OC, $n=7$ )

Sevoflurane (Sevorane ${ }^{\circledR}$, Abbot, İstanbul, Türkiye) was administered at $2 \%$ volume inspiratory concentration, $61 . \mathrm{min}^{-1}$ in $100 \% \mathrm{O}_{2}$ for 2 hours. After administration of anaesthesia, the abdomens of the rats were opened immediately and intra abdominal blood samples were obtained from the abdominal aorta. All the rats were then euthanized by $50 \mathrm{mg} \cdot \mathrm{kg}^{-1}$ ketamin administration. Preserving the tissue integrity by avoiding trauma, liver biopsy samples were obtained.

\section{Biochemical analysis}

The liver tissues were first washed with cold deionized water to discard blood contamination and then homogenized in a homogenizator. Measurements on cell contest require an initial preparation of the tissues. The preparation procedure may involve grinding of the tissue in a ground glass tissue blender using a rotor driven by a simple electric motor. The homogenizator as a tissue blender similar to the typical kitchen blender is used to emulsify and pulverize the tissue (Heidolph Instruments GMBH\&CO KG Diax 900 Germany $\left.^{\circledR}\right)$ at $1000 \mathrm{U}$ for about $3 \mathrm{~min}$. After centrifugation at $10000 \mathrm{~g}$ for about $60 \mathrm{~min}$, the upper clear layer was taken. In this fraction, total nitric oxide synthase (T-NOS) activity and nitric oxide (NO) pool $\left(\mathrm{NO} \cdot+\mathrm{NO}_{2}^{-}\right)$were measured as described, respectively $(22,23)$. NOS activity method was based on the diazotization of sulfanilic acid by nitric oxide at acid $\mathrm{pH}$ and subsequent coupling to $\mathrm{N}$-(1-napthyl-ethylene diamine), which is the modification of a previous study (lit yazaraının ismi konabilir) (22-24). The analysis scheme of the NOS activity measurement method has been described in a previous study (24). The absorbance of complex formed with N-(1-napthyl-ethylene diamine), reflects the sum of $\mathrm{NO} \cdot$ and $\mathrm{NO}_{2}^{-}$levels in the reaction medium, which is termed 'the NO pool' in the present study. Measurement of the $\mathrm{NO}$ pool (mainly consisting of $\mathrm{NO}+\mathrm{NO}_{2}^{-}$) is also based on the same chemical reaction, in which to a greater extent nitric oxide (NO-), and to a lesser extent nitrite anion $\left(\mathrm{NO}_{2}^{-}\right)$, but not nitrate anion $\left(\mathrm{NO}_{3}^{-}\right)$, gives a diazotization reaction with sulfanilic acid. In this method, sodium nitroprusside is used as the chemical standard and the reaction scheme given for the NOS activity measurement, except for the incubation of the sample with arginine, is followed. The TBARS levels were determined in the same supernatant fraction by using the thiobarbituric acid method of Van Ye et al (25) and were expressed in nmol/mg protein.
A part of the homogenate was extracted in ethanol/chloroform mixture $(5 / 3 \mathrm{v} / \mathrm{v})$ to discard the lipid fraction, which caused interferences in the activity measurements of total superoxide dismutase (T-SOD) and total glutathione-S transferase (T-GST). After centrifugation at $10.000 \mathrm{x} g$ for $60 \mathrm{~min}$, the upper clear layer was removed and used for the analyses.

The SOD activity method is based on the measurement of absorbance increase at $560 \mathrm{~nm}$ due to reduction of NBT to $\mathrm{NBTH}_{2}$ (26). One unit of SOD activity was defined as the enzyme protein amount causing 50\% inhibition in $\mathrm{NBTH}_{2}$ reduction rate and the results were expressed in $\mathrm{U} / \mathrm{mg}$. protein.

The GST activity was assayed using the procedure described by Habig et al (27) using 1-chloro-2,4-dinitrobenzene (CDNB) as a substrate in ultraviolet (UV by sequential addition of $0.1 \mathrm{M}$ phosphate buffer, $\mathrm{pH} 6.5(1.5 \mathrm{~mL})$, enzyme preparation as above $(0.1$ $\mathrm{mL}), 50 \mathrm{mM}$ of reduced GSH solution in buffer $(0.2 \mathrm{~mL})$, and 25 mM CDNB solution in ethanol $(0.15 \mathrm{~mL})(2 \mathrm{~mL}$ of final volume of the routine incubation mixture). Enzyme activity was determined by continuously monitoring the change in absorbance at $340 \mathrm{~nm}$ for $3 \mathrm{~min}$ at $25^{\circ} \mathrm{C}$ with a Shimadzu UV-1601 spectrophotometer and results were expressed in $\mathrm{mIU} / \mathrm{mg}$ of protein. Protein amounts were measured as described by Lowry et al (28).

\section{Statistical analyses}

The statistical analyses were performed with the SPSS 12.0 software program and $\mathrm{p}<0.05$ was considered statistically significant. The findings were expressed as the mean \pm standard deviation (SD). The data were evaluated with the Kruskal-Wallis variance analysis. The variables with significance were evaluated by the Bonferroni corrected Mann-Withney U test.

\section{Results}

The mean weight of the young female rats and old female rats were similar in all groups. TBARS levels and GST, SOD, NOS enzyme activities are shown in Table 1 and in Figure 1-4. There were no significant difference at SOD, GST, NOS and TBARS levels between young and old rat groups. However, the mean TBARS levels of the Group I-YS were significantly higher than those of the Group I-YC ( $\mathrm{p}=0.016)$ and the Group II-OS was significantly higher than the Group II-OC ( $\mathrm{p}=0.0016)$ (Tab. 1 and Fig. 1). Similarly, the mean GST enzyme activity of the Group I-YS was significantly higher than that of the Group I-YC $(p=0.008)$

Tab. 1. The mean \pm SD values of GST (mIU/mg) SOD (U/mg), NOS ( $\mathrm{mIU} / \mathrm{mg})$, enzyme activities and TBARS $(\mathrm{nmol} / \mathrm{mg}$ ) levels in rat liver tissues (mean \pm SD).

\begin{tabular}{lcccc}
\hline Enzymes & $\begin{array}{c}\text { TBARS } \\
(\mathrm{nmol} / \mathrm{mg})\end{array}$ & $\begin{array}{c}\text { GST } \\
(\mathrm{mlU} / \mathrm{mg})\end{array}$ & $\begin{array}{c}\text { SOD } \\
(\mathrm{U} / \mathrm{mg})\end{array}$ & $\begin{array}{c}\mathrm{NOS} \\
(\mathrm{mlU} / \mathrm{mg}),\end{array}$ \\
\hline Group I-YC & $0,48 \pm 0,21$ & $9,38 \pm 0,55$ & $6,53 \pm 0,28$ & $4,40 \pm 1,60$ \\
Group I-YS & $0,99 \pm 0,28+$ & $15,78 \pm 2,37+$ & $11,12 \pm 1,34+$ & $6,63 \pm 1,81$ \\
Group II-OC & $0,63 \pm 0,22$ & $9,84 \pm 0,42$ & $7,16 \pm 1,39$ & $6,40 \pm 1,87$ \\
Group II-OS & $1,22 \pm 0,51^{*}$ & $15,31 \pm 1,72 *$ & $13,09 \pm 2,08^{*}$ & $6,73 \pm 0,84$ \\
\hline
\end{tabular}

TBARS - Thiobarbutiric Acid-Reactive Substances; GST - glutathione S-transferase; SOD - superoxide dismutase; NOS - Nitric Oxide Synthatase, $+p<0.05$ when compared to the Group I - YC, * $<0.05$ when compared to the Group II - OC 
702-706

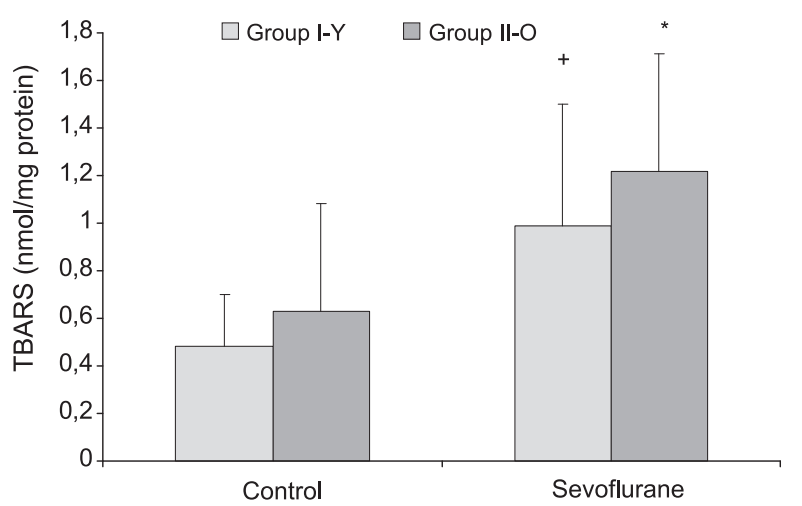

Fig. 1. The TBARS levels of the groups. Values are the mean \pm SD. $* p<0.05$, when compared to the Group II- OC, $+p<0.05$ when compared to the Group I- YC.

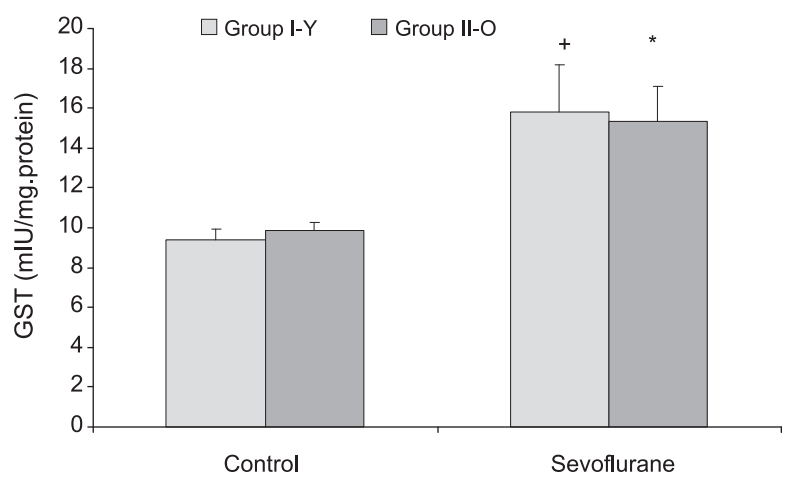

Fig. 2. The GST levels of the groups. Values are the mean \pm SD. * $p<0.05$, when compared to the Group II- $\mathrm{OC},+\mathbf{p}<\mathbf{0 . 0 5}$ when compared to the Group I- YC.

and the Group II-OS was significantly higher than the Group IIOC $(p=0.008)$ (Tab. 1 and Fig. 2). The increase of SOD enzyme activity in the Group I-YS was significantly higher than that of the Group I-YC ( $p=0.009)$ and the Group II-OS was significantly higher than that of the Group II- OC ( $p=0.008)$ (Tab. 1 and Fig. 3). There was no statistically significant difference between the groups when the mean NOS levels were compared (Tab. 1 and Fig. 4).

\section{Discussion}

The findings of the study indicated that rat groups, which had been exposed to sevoflurane, had higher SOD, GST, and TBARS levels than the control groups. It suggests that sevoflurane tends to create OS and increase antioxidant activity. On the other hand, the age was not found to be effective on OS in female Wistars.

In the clinical studies, Kharasch (25) and Kharasch et al (26) reported no hepatotoxic effects of sevoflurane, the new volatile anaesthetics, and insignificant rates of hepatic dysfunction (25, 27); nevertheless, the number of reported cases with hepatotoxicity associated with sevoflurane has increased in recent years (8-13).

The factor most responsible for hepatic injury following volatile anaesthetics use is trifluoroacetic acid (TFA) metabolite, which is formed through oxidative biotransformation of many anaesthetic agents, which then binds to subcellular proteins, resulting in cen-

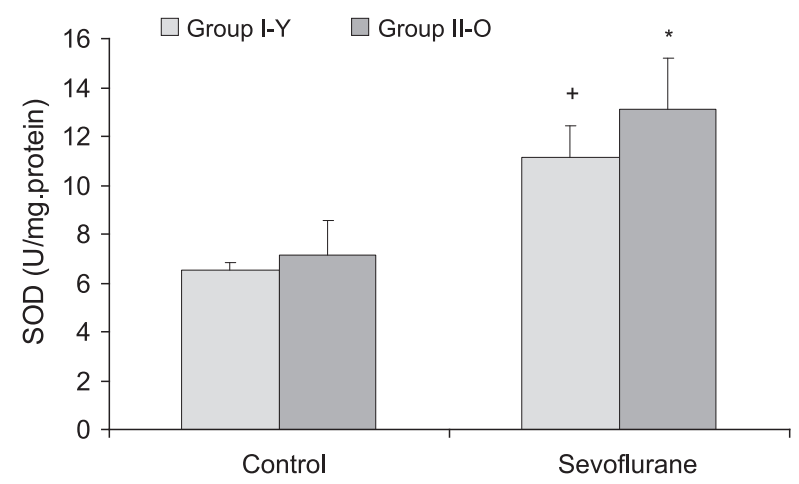

Fig. 3. The SOD levels of the groups. Values are the mean \pm SD. * $p<0.05$, when compared to the Group II- OC, + p $<0.05$ when compared to the Group I- YC.

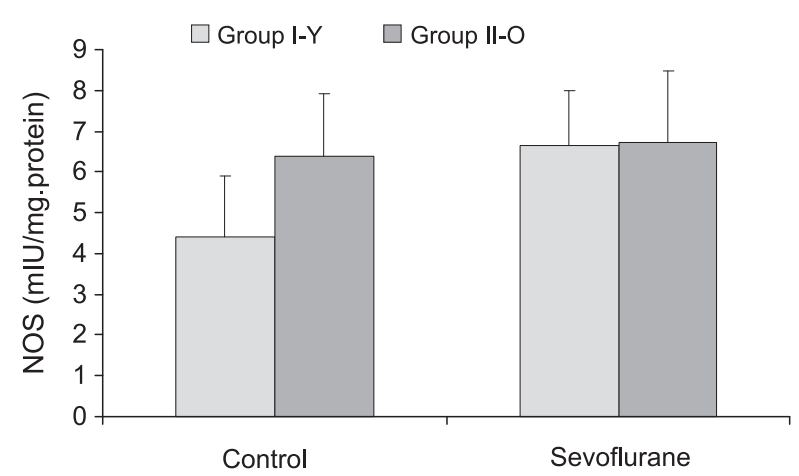

Fig. 4. The NOS levels of the groups. Values are the mean \pm SD.

trolobular necrosis of the liver. Sevoflurane, metabolized by mixedfunctioned oxidases in the liver, is the only inhalation anaesthetic that undergoes conjugation reaction for metabolite elimination, which is a different characteristic from those of the other anaesthetic agents (28). Sevoflurane is metabolized into Hexafluoroisopropanol (HFIP) and inorganic fluoride components by cytochrome (CYP) 450 2E1 enzyme in the liver (29). Although HFIP is a neurotoxic and hepatotoxic substance, so far its toxicity has not been reported in clinical application of sevoflurane $(30,31)$. Similarly, the organic fluoride resulting from sevoflurane metabolism is not expected to reach toxic levels and thus cause hepatic injury (29). On the other hand, Eger et al (32) have suggested a possible hepatotoxic effect of sevoflurane through binding of Compound A and hepatic proteins covalently, but have not described the mechanism thoroughly or supported their hypothesis in other studies (33).

Despite the reports of sevoflurane hepatotoxicity in recent years, its mechanism has not been explained $(9,10)$. Strikingly, both the reported cases are in the pediatric group of patients with a primary renal pathologies. Therefore, predisposition caused by renal pathologies should be investigated.

Free radicals, induced by several diseases, trigger OS, leading to the production of malondialdehyde (MDA). Because of the serious damaging potential of reactive oxygen species (ROS), cells depend on a wide spectrum of enzymatic and non-enzymatic antioxidant protective mechanisms. The primary intracellular defence 
mechanisms against oxidative injury include SOD, catalase, and glutathione peroxidase (GSHPx).

Isoflurane and halothane were shown to increase the susceptibility of cells to oxidant damage, desflurane was shown to increase the extend of oxidative status. The impact of sevoflurane anaesthesia on the oxidative and antioxidative balance is still controversial. While some investigators reported the lack of influence of sevoflurane on OS and antioxidant mechanics, other demonstrated that sevoflurane can cause ROS formation, whereas others researches have demonstrated the antioxidant properties of sevoflurane.

In our previous study (34) we show that sevoflurane did not significantly increase hepatic injury in the young male rats, meanwhile caused significantly more hepatic injury in the young female rats. In the old rats, sevoflurane inflicted more hepatic injury on both genders. Therefore, in this study, we investigated OS induced from sevoflurane on female rats and observed similar levels of OS between young and old rat groups.

Certain biochemical tests can guide in determining OS or antioxidant activity in the liver tissue samples. Oxygen radicals produced at the cellular level are detoxified by SOD and the final product is hydrogen peroxide $\left(\mathrm{H}_{2} \mathrm{O}_{2}\right)$, which is also detoxified by intracellular GSHPx enzyme. GST is one of the key enzymes that keeps the cellular membrane intact. GST, which is also known as non-Se GsHPx, is a part of antioxidant enzymatic system and plays a role in detoxification of lipid hydroxyl and peroxides (35). GST is localized in centrolobular hepatocytes; therefore, it is more specific than alanine aminotransferase (ALT) and aspartate aminotransferase (AST) for hepatic damage (36). GST is known to be an important marker of hepatotoxicity associated with volatile anaesthetic agents. In the study of Schimidt et al (37), an increase in GST levels was observed while ALT, AST, and gamma- glutamyl transferase (GGT) showed no change. MDA is currently estimated by measurement of TBARS. In this study, TBARS levels were studied as a marker of cellular membrane injury. TBARS is considered as a marker of lipid peroxidation injury via free radicals, and it is assessed by evaluating the effects of volatile anaesthetic agents (38).

NOS level is a marker of the endothelial function of OS (39). Briefly, it is possible to evaluate OS by studying TBARS and NOS levels and antioxidant defense systems based on superoxide levels such as SOD, GST, in aerobic organisms $(35,36,40)$. In our study, oxidant/antioxidant effects of sevoflurane anaesthetic agent was evaluated based on the levels of TBARS, and enzyme activity of NOS, GST and SOD in the rat liver tissue samples.

There are some researches who showed the transient and significant increase of plasma GST level after sevoflurane anaesthesia (41-43). Arslan et al (44) in their recent study showed that plasma GST level was higher than preoperative measurement, but was not significantly increased after desflurane anaesthesia in head and neck surgery patients. Koksal et al (45) studied plasma MDA and SOD enzyme activities in bronchoalveoler lavage cell after administration of desflurane or sevoflurane. Their results revealed that plasma MDA enzyme and SOD concentration activity was higher in desflurane group than in sevoflurane group. Consequently, Allaouchiche et al (46) showed in their swine study that administration of desflurane elevated the TBARS levels but not the SOD enzyme activities. Similarly Dikmen et al (47) indicated that SOD, GST enzyme activities and TBARS levels were significantly higher in anesthetized rat with desflurane than in the control group. On the other hand, Kang et al (48) studied young and old female rats and found that antioxidant treatment was more effective in decreasing TBARS concentration in adult rats. In addition, they reported that GST levels were lower in young rats than adult ones. In our research, both GST and SOD enzyme activities and TBARS levels were significantly higher in sevoflurane (young and old female rats) group than in the control (young and old female rat) group.

In conclusion, this study supports the literature data which indicates that sevoflurane brings on OS. Additionally, we are presenting the first data in literature that sevoflurane anaesthesia caused similar level OS in aged and young female rat. Limited number of animals in each group and no cardiovascular observation regarding to spontaneous respiration are thought to be the limitations of this study. The comparison of sevoflurane versus other inhalational anaesthetics by this term needs further clinical trials and the role of exposure time may be investigated.

\section{References}

1. Jackie L, Martin MD. Volatile anesthetics and liver injury: a clinical update or what every anesthesiologist should know: Can J Anesth 2005; 52: $125-129$.

2. Brunt EM, White H, Marsh JW, Holtman B, Peters MG. Fulminant hepatic failure after repeated exposure to isoflurane anesthesia: a case report. Hepatology 1991; 13: 1017-1021.

3. Weitz J, Kienle P, Böhrer H, Hofman W, Theilmann L, Otto G. Fatal hepatic necrosis after isoflurane anesthesia. Anesthesia 1997; 52: 892-895.

4. Cousins MJ, Plummer JL, Hall PD. Risk factor for halothane hepatitis. Aust N Z Surg 1989; 59: 5-14.

5. Durak I, Guven T, Birey M, Oztürk HS, Kurtipek O, Yel M et al. Halothane hepatotoxicity and hepatic free radical metabolism in guinea pigs; the effects of vitamin E. Can J Anaesth 1996; 43: 741-748.

6. Carbonell LF, Nadal JA, Llanos C, Hernandez I, Nava E, Diaz J. Depletion of liver glutathione potentiates the oxidative stress and decreases nitric oxide synthesis in rat endotoxin shock model. Crit Care Med 2000; 28: 2002-2006.

7. Behne M, Wilke HJ, Harder S. Clinical Pharmacokinetics of sevoflurane. Clin Pharmacokinet 1999; 36: 13-26.

8. Chung PC, Chiou SC, Lien JM, Li AH, Wong CH. Reproducible hepatic dysfunction following separate anesthesia with sevoflurane and desflurane. Chang Gung Med J 2003; 26: 357-362.

9. Reich A, Everding AS, Bulla, M, Brinkmann OA, Van Aken H. Hepatitis after sevoflurane exposure in an infant suffering from primary hyperoxaluria type 1. Anesth Analg 2004; 99: 370 -372.

10. Youngho J, Insoo K. Severe hepatotoxicity after sevoflurane anesthesia in a child with mild renal dysfunction. Paediatr Anaesth 2005; 15: 1140-1144.

11. Alotaibi WH. Severe hepatic dysfunction after sevoflurane exposure. Saudi Med J 2008; 29: 1344-1346.

12. Turillazzi E, D'Ericco S, Neri M, Riezzo I, Fineschi V. A fatal case of fulminant hepatic necrosis following sevoflurane anesthesia. Toxicologic Pathology 2007; 35: 780-785. 
13. Lehman A, Neher M, Kiesling AH, Isgro F, Koloska A, Boldt J. Case report: Fatal hepatic failure after aortic valve replacement and sevoflurane exposure. Can J Anesth 2007; 54: 917-921.

14. Tsujimoto S, Kato H, Minamoto $Y$ et al. Comparison of postoperative liver dysfunction following halothane and sevoflurane anesthesia in women undergoing mastectomy for cancer. J Anesth 1995; 9:129-134.

15. Nishiyama T, Yokoyama T, Hanaoka K. Effect of sevoflurane and isoflurane anesthesia on arterial ketone body ratio and liver funtion. Acta Anaesthesiol Scand 1999; 43: 347-351.

16. Iwanaga Y, Komatsu H, Yokono S, Ogli K. Serum glutathione Stransferase alpha as a measure of hepatocellular function following prolonged anaesthesia with sevoflurane and halothane in paediatric patients. Pediatr Anesth 2000; 10: 395-398.

17. Fish RE,Brown MJ,Danneman PJ,KarasAZ.Anesthesia andAnalgesia in Laboratory Animals (2nd ed) Elsevier, San Diego, CA, U.S.A. 2008, pp 243.

18. Bucala R, Tracey KJ, Cerami A. Advanced glycosylation products quench nitric oxide and mediate defective endothelium- dependent vasodilatation in experimental diabetes. J Clin Invest 1991; 87: 432-438.

19. Ignarro LJ, Buga GM, Wood KS, Byrns RE, Chaudhuri G. Endothelium-derived relaxing factor produced and released from artery and vein is nitric oxide. Proc Natl Acad Sci USA 1987; 84: 9265-9269.

20. Durak I, Kavutcu M, Kacmaz M, Avci A, Horasanli E. Effects of isoflurane on nitric oxide metabolism and oxidant status of guinea pig myocardium. Acta Anaesthesiol Scand 2001; 45: 119-122.

21. Van Ye TM, Roza AM, Pieper GM, Henderson J Jr, Johnson CP, Adams MB. Inhibition of intestinal lipid peroxidation does not minimize morphological damage. J Surg Res 1993; 55: 553-558.

22. Durak I, Canbolat O, Kavutcu M, Oztürk HS, Yurtaslani Z. Activities of total, cytoplasmic and mitochondrial superoxide dismutase enzymes in sera and pleural fluids from patient with lung cancer. J Clin Lab Anal 1996; 10: 17-20.

23. Habig WH, Pabst MJ, Jakoby WB. Glutathione S-transferases. The first enzymatic step in mercapturic acid formation. J Biol Chem 1974; 249: 7130-7139.

24. Lowry O, Rosenbrough N, Farr L, Randall RJ. Protein measurement with folin phenol reagent. J Biol Chem 1951; 182: 265-275.

25. Kharash ED. Metabolism and toxicity of the new anesthetic agents. Acta Anesthesiol Belg 1996; 47: 7-14.

26. Kharasch ED, Frink EJ, Zager R, Bowdle TA, Artru A, Nogami WM. Assessment of low-flow sevoflurane and isoflurane: effects on renal function using sensitive markers of tubular toxicity. Anesthesiology 1997; 86: 1238-1253.

27. Kenna JG, Jones RM. The organ toxicity of inhaled anesthetics. Anesth Analg 1995; 81: 51-66.

28. Preckel B, Bolten J. Pharmacology of modern volatile anaesthetics. Best Pract Res Clin Anaesthesiol 2005; 19: 331-348.

29. Kharasch ED, Thummel KE. Identification of cytochrome P450 2E1 as the predominant enzyme catalyzing human liver microsomal defluorination of sevoflurane, isoflurane, and methoxyflurane. Anesthesiology 1993; 79: 795-807

30. Biebuyck JF, Phill MB, Eger I. New inhaled anaesthetics. Anesthesiology 1994; 80: 906-914.

31. Smith I, Nathanson M, White PF. Sevoflurane- a long awaited volatile anesthetic. Br J Anaesth 1996; 76: 435-445.
32. Eger EI 2nd, Koblin DD, Bowland T, Ionescu P, Laster MJ, Fang Z. Nephrotoxicity of sevoflurane versus desflurane anesthesia in volunteers. Anesth Analg 1997; 84: 160-168.

33. Eger EI. Characteristics of anesthetic agents used for induction and maintenance of general anesthesia. Am J Health-Syst Pharm 2004; 61: $3-10$.

34. Arslan M, Ozköse Z, Akyol G, Barit G. The age-and gender-dependent effects of desflurane and sevoflurane on rat liver. Exp Toxicol Pathol 2010; 62: 35-43.

35. Prabhu KS, Reddy PV, Jones EC, Liken AD, Reddy CC. Characterization of a class alpha glutathione-S-transferase with glutathione peroxidase activity in human liver microsomes. Arch Biochem Biophys 2004; 424: 72-80.

36. Richard MJ, Portal B, Meo J, Coudray C, Hadjian A, Favier A. Malondialdehyde kit evaluated for determining plasma and lipoprotein fractions that react with thiobarbituric acid. Clin Chem 1992; 38: 704-709.

37. Schmidt CC, Suttner SW, Piper SN, Nagel D, Boldt J. Comparison of the effects of desflurane and isoflurane anaesthesia on hepatocellular function assessed by alpha glutathione S-transferase. Anaesthesia 1999; 54: 1204-1219.

38. Bezerra F, Rezende AA, Rodrigues SJ, Almeida MG. Thiobarbituric acid reactive substances as an index of lipid peroxidation in sevofluranetreated rats. Rev Bras Anestesiol 2004; 54: 640-649.

39. Wolin MS, Ahmad M, Gupte SA. The sources of oxidative stress in the vessel wall. Kidney Int 2005; 67: 1659-1661.

40. Sessa WC. The nitric oxide synthase family of proteins. J Vasc Res 1994; 31: 131-143.

41. Suttner SW, Schmidt CC, Boldt J, Hüttner I, Kumle B, Piper SN. Low-flow desflurane and sevoflurane anesthesia minimally affect hepatic integrity and function in elderly patients. Anesth Analg 2000; 91: 206-212.

42. Tiainen $\mathbf{P}$, Lindgren $\mathbf{L}$, Rosenberg $\mathbf{P H}$. Changes in hepatocellular integrity during and after desflurane or isoflurane anaesthesia in patients undergoing breast surgery. Br J Anaesth 1998; 80: 87-89.

43. Röhn KD, Suttner SW, Boldt J, Schölhorn TA, Piper SN. Insignificant effect of desflurane-fentanyl-thiopental on hepatocellular integrity-a comparison with total intravenous anaesthesia using propofolremifentanil. Eur J Anesth 2005; 22: 209-214.

44. Arslan M, Kurtipek O, Dogan AT, Unal Y, Kizil Y, Nurlu N et al. Comparison of effects of anaesthesia with desflurane and enflurane on liver function. Singapore Med J 2009; 50: 73-77.

45. Koksal GM, Sayilgan C, Aydin S, Uzun H, Oz H. The effects of sevoflurane and desflurane on lipid peroxidation during laparoscopic cholecystectomy. Eur J Anaesth 2004; 21: 217-220.

46. Allaouchiche B, Debon R, Goudable J, Chassard D, Duflo F. Oxidative stress status during exposure to propofol, sevoflurane and desflurane. Anesth Analg 2001; 93: 981-985.

47. Dikmen B, Unal Y, Pampal HK, Nurlu N, Kurtipek O, Canbolat O et al. Effects of repeated desflurane and sevoflurane anesthesia on enzymatic free radical scavanger system. Mol Cell Biochem 2007; 294: 31-36.

48. Kang MY, Tsuchiya M, Packer L, Manabe M. In vitro study on antioxidant potential of various drugs used in the perioperative period. Acta Anaesthesiol Scand 1998; 42: 4-12.

Received December 2, 2010. Accepted September 20, 2012. 